\title{
Workplace insurance woes
}

\author{
Cracking Health Costs: How to Cut Your \\ Company's Costs and Provide Employees \\ Better Care \\ Tom Emerick and Al Lewis \\ John Wiley and Sons; 2013

\section{Surviving Workplace Wellness with Your Dignity, Finances and (Major) Organs Intact \\ Al Lewis and Vik Khanna \\ The Healthcare Blog; 2014}

$\mathrm{T}$ he United States has a problem with health care. In terms of hard health outcomes such as life expectancy, child survival and other measures of health-related quality of life, the US stands out head and shoulders above other nations in delivering cost-ineffective health care. Americans who are not poor, old, veterans or in the military get their health insurance largely from their employer. This leaves employers with a bill that is often their second- or third-highest business expense. They try to manage the burden with a panoply of middlemen, including vendors, brokers and benefits consultants, who work the interface between the insurers and the employers, selling health benefits "advice" while taking their cut (a percentage of spending). This results in excessive medicalization, inappropriate care and overtreatment, with employers (and in turn employees) getting stuck with the growing bill.

Cracking Health Costs and Surviving Workplace Wellness both address this conundrum with a surprising dose of Dave Barry-esque humour and a welcome dollop of fifth-grade math.

The two long-in-the-tooth US health care experts behind Cracking Health Costs have written a very funny insider's book. Their helpful tips can jolt US employers to realize how they're being taken to the cleaners. Their suggestions could help make American health care more cost-effective, as well as enlighten

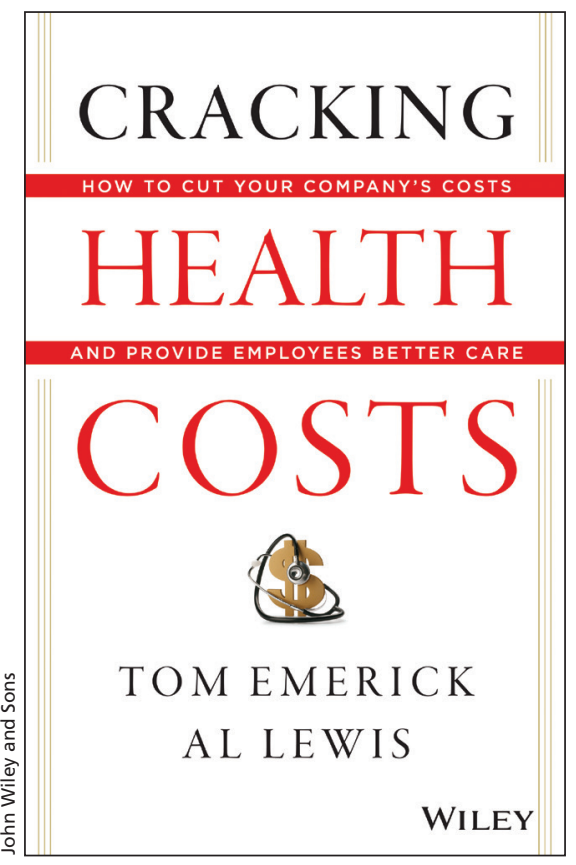

Canadian human resource managers who increasingly rely on vendors to sort through private insurance woes. Even so, the book frequently prompts the kind of laughter that makes coffee shoot out of your nose. One of the chapters is titled: "It's Time for the Wellness Industry to Admit to Doping," a mild way to introduce a central theme of the book, that the promoters of employer-sponsored wellness programs are mostly high on their own rhetoric.

Probing some of the central tenets of US-style health care, Emerick and Lewis write that middlemen frequently tell employers they can save more money in the long run if they spend more money on things such as "wellness programs." These programs sound good on paper, but as the two authors reveal, they range from being bald-faced lies to merely grandiose promises supported by tortured mathematics. The authors proffer a different philosophy by writing "we will propose to reduce your company's health care spending by spending less money on your company's health care," a frank

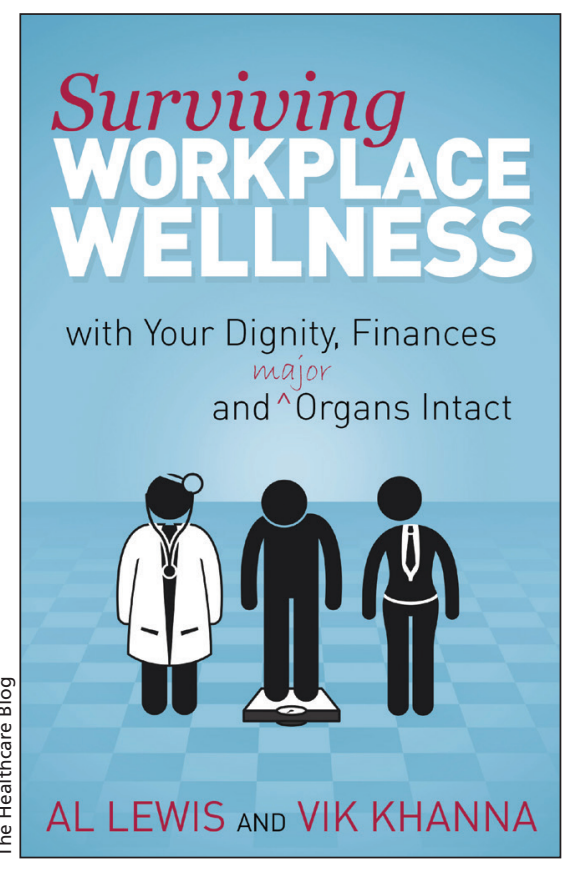

tautology that they say runs against the grain of most health advice being given out by vendors and brokers. Emerick and Lewis break apart components of a typical insurer's basket of goods, such as drug benefit programs and workplace wellness programs, which are known for their ability to overpromise and underdeliver year after year. The authors show how those promises, such as massive returns on investment in wellness programs, don't stand simple tests of logic and plausibility.

Even though the authors focus on the crazy, broken US health-insurance world, all Canadians could learn a few things and arm themselves with hard questions when private insurers are trying to sell them products and promises. My advice: if you work in human resources in Canada and you are wondering what actually works to keep employees healthy without breaking the bank, you need to read this book and you need to read it fast. Just avoid hot beverages while doing so.

The dangers inflicted on Americans from too much medicine, too much 
screening and too much nuisance intrusion into the lives of ordinary working people by employer-sponsored health and wellness programs is not yet high on the radar in Canada. In Surviving Workplace Wellness, however, two funny men are making sure it is on flagrant display in the US. And boy are they having fun doing so.

Surviving Workplace Wellness is perhaps even more pertinent to Canada than Cracking Health Costs and sets fire to the cottage industry known as "workplace wellness," which authors Lewis and Khanna call the "poke, pry, prod and bribe" approach to keeping employees healthy and productive. For them, the answer to the "What is workplace wellness?" Jeopardy question is this: "With a big assist from the federal government, this is the dumbest idea your employer's human resources department has ever come up with." Not mincing words, their arguments are buttressed by a critical look at the numbers, the prom- ises and the reality. The authors argue that most workplace wellness programs not only don't save employers money, they push even more invasive medicine on employees, lowering morale and, in some cases, actually delivering the opposite of wellness.

Certainly programs that may help employees eat better, be more active and build morale without drawing their blood or subjecting them to invasive questions about their lifestyle (what's known as the health risk assessment) have some merit. But as is clear from the book's many examples, some employers have gone too far, even penalizing workers for not participating in these workplace programs.

If you are an employer, a human resources manager or an employee in Canada who depends on private health insurance, you might be tempted by the kinds of US-style health and wellness programs that are rigorously excoriated in this book. If so, you need to heed the words of Lewis and Khanna, who re- mind us of the dangers that await: "Most people have just accepted these pry-poke-and-prod indignities as part of their job. But it's more than indignity and inconvenience. You are being ripped off, misled and even harmed as a result of these programs."

For health care systems at risk of overtreating and overspending at the expense of employees' well-being, these books remind us that cracking health costs so that employees can survive with their dignity, finances and major organs intact are both laudable and achievable goals.

\section{Alan Cassels BA MPA}

Faculty of Human and Social Development, University of Victoria, Victoria, BC

Competing interests: Alan Cassels is collaborating with Vik Khanna and Al Lewis on developing an app that will help consumers make evidence-based health care choices; he declares that he has no financial interests connected to their consulting work or the sales of their books.

CMAJ 2015. DOI:10.1503/cmaj.140677 